\title{
Optimization of photo-catalytic degradation of oil refinery wastewater using Box-Behnken design
}

\author{
Emmanuel Kweinor Tetteh ${ }^{\dagger}$, Dushen Bisetty Naidoo, Sudesh Rathilal \\ Faculty of Engineering and the Built Environment, Department of Chemical Engineering, Durban University of Technology, Durban 4000, South Africa
}

\begin{abstract}
The application of advanced oxidation for the treatment of oil refinery wastewater under UV radiation by using nanoparticles of titanium dioxide was investigated. Synthetic wastewater prepared from phenol crystals; Power Glide SAE40 motor vehicle oil and water was used. Response surface methodology (RSM) based on the Box-Behnken design was employed to design the experimental runs, optimize and study the interaction effects of the operating parameters including catalyst concentration, run time and airflow rate to maximize the degradation of oil (SOG) and phenol. The analysis of variance and the response models developed were used to evaluate the data obtained at a 95\% confidence level. The use of the RSM demonstrated the graphical relationship that exists between individual factors and their interactive effects on the response, as compared to the one factor at time approach. The obtained optimum conditions of photocatalytic degradation are the catalyst concentration of $2 \mathrm{~g} / \mathrm{L}$, the run time of $30 \mathrm{~min}$ and the airflow rate of $1.04 \mathrm{~L} / \mathrm{min}$. Under the optimum conditions, a $68 \%$ desirability performance was obtained, representing $81 \%$ and $66 \%$ of SOG and phenol degradability, respectively. Thus, the hydrocarbon oils were readily degradable, while the phenols were more resistant to photocatalytic degradation.
\end{abstract}

Keywords: Box-Behnken design, Oil refinery, Photocatalytic degradation, Response surface methodology, $\mathrm{TiO}_{2}$

\section{Introduction}

The recent industrialisation and social economic growth envisaged in the world is associated with major environmental concerns. Thus, the demand on petroleum and petrochemical useful products produced from crude oil is escalating with a high consumption rate of water [1]. It has been estimated that about 246-341 L of water is consumed in processing a barrel of crude oil [2, 3]. However, based on the oil refinery industry size, capacity, type of crude oil, products and complexity of operation, it is in turn generates about 0.4-1.6 times the quantity of crude oil processed as wastewater. According to El-Naas et al. [4], the demand on energy is expected to rise over the next two decades and oil will account for about 32\% of the world's energy supply by 2030 . This signifies that oil refinery wastewater (ORW) will continue to pose threats to the ecosystem if not treated before discharge into the water bodies, due to wastewater treatment limitations in relating to recalcitrant compounds, which resist biological decomposition [4]. This has led to strict environmental protection bylaws in the wastewater treatment industries to correspondently preserve the natural ecosystem.

Generally, ORW contains diverse recalcitrant contaminants as inorganic substances, soap oil and grease (SOG), phenols, sulphides and ammonia contributing to high chemical oxygen demand (COD) [5]. As a result, many researchers have developed strong interest in optimizing and developing technologies to improve the discharge water quality to meet the stringent environmental regulations. Some of these conventional processes are based on integrated physicochemical, mechanical and biological treatment process systems. These include dissolved air flotation (DAF) [6], coagulation [2], membrane bioreactors [7] and photocatalytic processes [8]. However, due to the variation in ORW composition, some of the aforementioned methods are not adequate as they transform the phase of the pollutants from one form to another without complete removal of the oil residual from the effluent [9]. Subsequently biological treatments of this industrial wastewater is not possible, hence modern and fastidious technologies like the advanced oxidation process (AOP) has been proposed to encourage sustainable and eco-friendly industrial operations [5]. This is because the AOP has the ability
This is an Open Access article distributed under the terms of the Creative Commons Attribution Non-Commercial License (http://creativecommons.org/licenses/by-nc/3.0/) which permits unrestricted non-commercial use, distribution, and reproduction in any medium, provided the original work is properly cited.

Copyright (C) 2019 Korean Society of Environmental Engineers
Received June 26, 2018 Accepted January 17, 2019

${ }^{\dagger}$ Corresponding author

Email: ektetteh34@gmail.com

Tel: +27-313732123 Fax: +27-866741148

ORCID: 0000-0003-1400-7847 
to degrade the biological compositions and lower the toxic resistant organic components of the ORW. In response, much emphasis has been placed on introducing photo-catalytic degradation (PCD) as a water saving initiative integrated in an advanced ORW treatment process [10]. Studies have shown that the oxidative process of the PCD makes it more advantageous as a final polishing treatment process for effective degradation of toxic residuals [8].

Recently nano-photocatalysts like titanium dioxide $\left(\mathrm{TiO}_{2}\right)$, Zinc oxide $(\mathrm{ZnO})$ and Tungsten trioxide $\left(\mathrm{WO}_{3}\right)$ have been employed in the AOD process, where the $\mathrm{TiO}_{2}$ has been used extensively for the removal of organic compounds. $\mathrm{TiO}_{2}$ is cost-effective with a high photocatalytic activity, is non-toxicity and has chemical stability, which makes it superior among the rest of the catalysts $[8,11]$. This is because the PCD involves the generation of a hydroxyl radical $\left(\mathrm{OH}^{-}\right)$which is used for the degradation of the organics. According to Somensi et al [12], heterogeneous PCD can occur in the presence of a semiconductor such as $\mathrm{TiO}_{2}$ and $\mathrm{ZnO}$, such that the hydroxyl radical produced acts as the primary agent responsible for the oxidation of several aqueous organic contaminants as presented below [11]:

Photoexcitation: $\mathrm{TiO}_{2}+h v \rightarrow e^{-}+h^{+}$

Charge-carrier trapping of $\mathrm{e}^{-}: e_{C B}^{-} \rightarrow e_{T R}^{-}$

Charge-carrier trapping of $\mathrm{h}^{+}: h_{V B}^{+} \rightarrow h_{T R}^{+}$

Electron-hole recombination: $e_{T R}^{-}+h_{V B}^{+}\left(h_{T R}^{+}\right) \rightarrow e_{C B}^{-}+$heat $(4)$

Photoexcited e scavenging: $\left(\mathrm{O}_{2}\right)_{a d s}+e^{-} \rightarrow \mathrm{O}_{2}^{--}$

Hydroxyl $\mathrm{h}^{+}$scavenging: $\mathrm{OH}+h^{+} \rightarrow \mathrm{OH}^{\bullet}$

Photo degradation by $\mathrm{OH}^{\bullet}: \mathrm{R}-\mathrm{H}+\mathrm{OH}^{\bullet} \rightarrow \mathrm{R}^{\prime}{ }^{+} \mathrm{H}_{2} \mathrm{O}$

The above photocatalytic reaction mechanism indicates that the degradation method is a clean technology and can be applied to the treatment of several wastewater applications where unwanted organics may exist [12]. Similar thoughts are shared by Ghasemi et al. [13], where it was reported that some of the key benefits of using $\mathrm{TiO}_{2}$ for PCD include the fact that no sludge formation occurs in the complete elimination of the contaminants. In addition, the use of the $\mathrm{TiO}_{2}$ particles due to its ability to remove organics and in some cases inorganic pollutants, makes it appealing. So far, various types of $\mathrm{PCD}$ viz $\mathrm{TiO}_{2} / \mathrm{UV}$ light process, $\mathrm{H}_{2} \mathrm{O}_{2} / \mathrm{UV}$ light process and Fenton's reactions have gain much attention in the wastewater settings. The PCD, as one of the emerging techniques, has some setbacks in operations which affects the $\mathrm{TiO}_{2}$ reaction rate, hence requires an optimized condition to enhance effective degradation of the contaminants [8, 11]. Some of the main factors that can affect the performance of PCD with $\mathrm{TiO}_{2}$ include photo catalyst concentration, $\mathrm{pH}$ of the solution, reaction temperature, concentration of the pollutants, presence of inorganic ions, flow rate of air sparged, light intensity or wavelength and reaction time [13].

Optimizing PCD operating conditions is the ultimate goal of many researchers, where there is a knowledge gap on the interactive effects of the input variables on the system outputs. Yan [7] explains that high pollutant concentration can retard the PCD efficiency and can inhibit the catalyst as the $\mathrm{TiO}_{2}$ surface becomes saturated. For instance, Lazar et al. [11] reported on phenol degradation where a high increase in the catalyst dosage reduced the generation of the hydroxyl radicals because there were fewer spots present to adsorb the hydroxyl ion. Ghasemi et al. [13] then used a catalyst within the range of 0.5 to 5 $\mathrm{g} / \mathrm{L}$ to obtain above $65 \%$ degradation of ORW contaminants. Similarly, a study carried out by Somesi et al [12] for PCD of COD from ORW at a catalyst dosage of $6 \mathrm{mg} / \mathrm{L}$ produced a degradation of about $67 \%$ and $65 \%$, respectively obtained for $\mathrm{pH}$ values of 5 and 6 .

However, the conventional way of optimization usually increases the number of experimental runs. This is time consuming with an increase in experimental budget. Response surface methodology (RSM) can therefore be employed for process modelling and optimization in the field of PCD of ORW. This is because, RSM is data driven which is usually used to estimate the relationship between the target variable and input variables. Afterwards, the derived models are used to approximate the optimum conditions of the input variables to minimize or maximize the targeted variable [12].

In this study, the use of RSM was employed to evaluate the interactive factors. The RSM has been applied in several wastewater treatment industries such as the oil refinery for DAF optimization as well as processes with multiple input variables which has an influence on the system performance [14, 15]. RSM, as defined by Tetteh and Rathilal [14], is a collection of statistical and mathematical techniques used for experimental design, optimization and improving processes. The most commonly used RSM designs are Central Composite design (CCD) and the Box-Behnken design (BBD). For CCD, points at the apexes of the cube gives rise to certain restrictions as the testing of these points become impossible due to the constraints of physical processes therefore increasing costs and making BBD more favourable. The BBD is different to the CCD design as it does not have a factorial design component present. Thus, the BBD constitutes an independent quadratic design with treatment allowing three levels for each factor such as the low, centre and high points. This makes it applicable in industrial research as it is an economical design with low resource requirements [14]. The BBD is known to have good design properties namely little co-linearity as well as it being insensitive to outliers and missing data. The BBD default design aims to improve prediction by using the average prediction variance. Therefore, BBD, adapted from RSM, was employed for the optimization of ORW exposed to micro $\mathrm{TiO}_{2}$ photocatalyst under ultraviolet lighting and aeration conditions. The factors under study are the catalyst concentration, reaction time and aeration flux on the degradation of the responses such as SOG and phenols. 


\section{Materials and Methods}

\subsection{Effluent Sample and Analytical Methods}

A synthetic oil-water emulsion concentration of 10,000 mg/L was prepared by adding $3 \mathrm{mg} / \mathrm{L}$ phenol crystals and $40 \mathrm{mg} / \mathrm{L}$ Power Glide SAE40 motor vehicle oil (Engen, SA) to a local South Africa municipal water. The characterisation of the effluent was done in accordance with the American Public Health Association [16] as depicted in Table 1. The phenol was tested with the use of the ThermoFisher - Gallery Discrete Analyser. SOG analysis was measured with the liquid-liquid extraction coupled with gravity separation techniques. This method conforms to the standard methods for the examination of water and wastewater in an oil refinery as reported by Tetteh et al [17]. By analysing SOG and phenol degradation percentage after the experimental stipulated time, the efficiency of the process was examined using the following equation:

$$
\% \text { removal efficiency }=\frac{s_{0}-s}{s_{0}} \times 100
$$

In this equation, $S_{0}$ and $S$ are the initial sample and final sample parameters, respectively.

Table 1. Characteristics of ORW Sample

\begin{tabular}{lc}
\hline Component & Value \\
\hline SOG (mg/L) & 50 \\
Phenol (mg/L) & 10 \\
Phosphate (mg/L) & 0.6 \\
Calcium hardness (mg/L) & 37 \\
M-Alkalinity (mg/L) & 77 \\
Total Dissolved Solids (TDS) (mg/L) & 233 \\
pH & 7.13 \\
Iron (mg/L) & 6 \\
Chlorides (mg/L) & 99 \\
Sulphates (mg/L) & 28 \\
Silica (mg/L) & 60 \\
\hline
\end{tabular}

\subsection{Nanocatalyst $\left(\mathrm{TiO}_{2}\right)$}

Nanocatalyst $\left(\mathrm{TiO}_{2}\right)$ as SACHTLEBEN RKB6 supplied by Huntsman Tioxide South Africa (Pty) was employed in this study. The SACHTLEBEN RKB6 is a micronized rutile $\mathrm{TiO}_{2}$ pigment treated with Alumina and Zirconia compounds as depicted in Table 2.

\subsection{Experimental Setup}

The photocatalytic degradation of the synthetic oil-emulsion wastewater was performed with the experimental setup as depicted in Fig. 1. This setup was configured with two-reaction vessels of 1 litre volume each. The sparger had pinholes that were 0.5 $\mathrm{cm}$ apart and the length of the sparger was $9 \mathrm{~cm}$. The air sparged was supplied by a DARO Twin aquarium air pump, which had
Table 2. Physical and Crystallite Properties of SACHTLEBEN RKB6 (Huntsman Tioxide South Africa Pty)

\begin{tabular}{lc}
\hline Properties & Value \\
\hline White powder content & $94 \%$ purity \\
Phase mixture & Rutile $94 \%$, Anatase $6 \%$ \\
Surface treatment & Alumina, Zirconia \\
Organic treatment & Present \\
Surface gravity & $4.1 \mathrm{~g} / \mathrm{cm}^{3}$ \\
Crystal size & $0.23 \mathrm{~m}$ \\
Loss at $105^{\circ} \mathrm{C}$ & $0.60 \%$ \\
Bulk density & $1.1 \mathrm{~g} / \mathrm{cm}^{3}$ \\
Oil absorption & $18 \mathrm{~cm}^{3} / 100 \mathrm{~g} \mathrm{pigment}$ \\
Durability & $\mathrm{High} \mathrm{durable}$ \\
ISO 591 classification & $\mathrm{R}^{2}$ \\
CAS No & $13463-67-7$ \\
\hline
\end{tabular}

double outlets $\left(\mathrm{X}_{1}\right.$ and $\mathrm{X}_{2}$ ), and a high and low flow setting. Two air pumps were used to service the four reaction vessels used. All tubing used for the supply of air was $4.5 \mathrm{~mm}$ silicone tubing. The irradiating light source (UV light) used was a radiant fluorescent T8 black light blue bulb of $18 \mathrm{~W}$. This was used to activate the $\mathrm{TiO}_{2}$ catalyst for the advanced oxidation reaction.

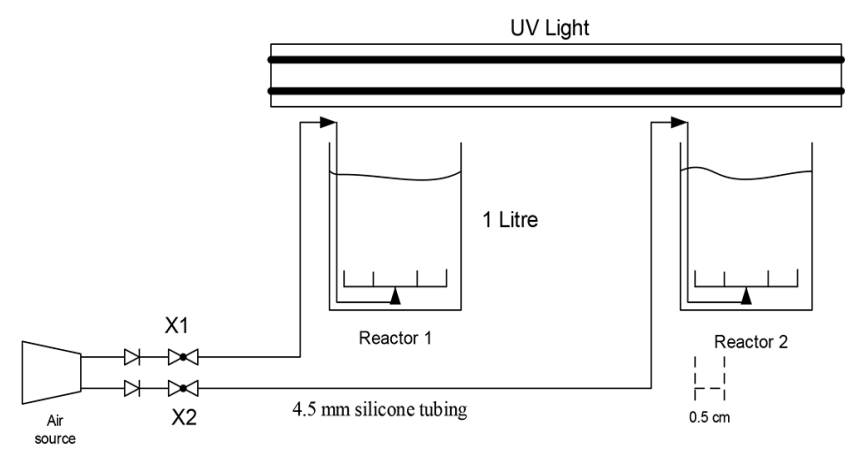

Fig. 1. Schematic diagram of photocatalytic degradation setup.

\subsection{Response Surface Methodology (RSM)}

To begin with, the RSM one factor at time (OFAT) approach was employed to study the effect of individual factors for the photocatalytic degradation of the ORW based on their ranges from literature. The three parameters selected were the catalyst concentration (A), run time (B) and airflow rate (C). Also, by employing the BBD, 17 experimental runs were designed with design Expert 10 software (Stat Ease Inc., USA). Table S1 depicts the BBD matrix of the 3 factor levels according to literature. Each numeric factor is set to 3 levels and 5 centre points. The centre points are duplicated for every combination of the categorised factor levels (Table S2). The results obtained were then fitted on a response surface quadratic model with oil (SOG) and phenol as the response variables.

In response surface modelling, a quadratic polynomial equation 
was used to analyse the correlation between the targeted response (Y) and the input factors as follows Eq. (9):

$$
Y=\beta_{0}+\sum_{i=1}^{k} \beta_{i} x_{i}+\sum_{i=1}^{k} \beta_{i i} x_{i}^{2}+\sum_{1 \leq i \leq j}^{k} \beta_{i j} x_{i} x_{j}+\varepsilon(9)
$$

In the above equation, $y$ represents the target variable of the photocatalytic efficiency, $\beta_{0}$ is a constant, $\beta_{i j}, \beta_{i i}, \beta_{i}$ are the coefficients of regression for interaction effects, $x_{i}, x_{j}$ are independent variables of process, and $\varepsilon$ represents the error [6]. The statistical analysis via analysis of variance (ANOVA) was performed and a model was suggested. To ensure the significance and the accuracy of the quadratic model obtained by using the RSM parameters like the regression coefficient $\left(R^{2}, R_{\text {adj. }}^{2}\right.$ ), probability value ( $p$-values), adequate precision and fisher variation ratio (F-values) were determined. This was evaluated with respect to a 95\% confidence level. Finally, response surface three-dimensional (3D) graphs were plotted to illustrate the effects of interaction terms on the degradation of oil (SOG) and phenol.

\section{Results and Discussion}

\subsection{Effects of Catalyst Concentration}

In order to evaluate the extent of oil (SOG) and phenol degradation, the photolysis and adsorption tests were carried out by varying the catalyst concentration at $2 \mathrm{~g} / \mathrm{L}, 5 \mathrm{~g} / \mathrm{L}$ and $8 \mathrm{~g} / \mathrm{L}$. It was observed that for a high catalyst concentration, there is an increased rate of adsorption of the contaminants onto the $\mathrm{TiO}_{2}$ catalyst surface [13]. This produced more hydroxyl radicals and as a result increased the oxidation process as presented in Fig. S1.

Fig. S1 shows that an increase in the catalyst concentration had a direct influence on the degradation of the contaminants. There was a greater degradation of the oil than the phenols. On average, oil (SOG) degradation was found to be $60 \%, 88 \%$ and 98\% for catalyst concentration of $2 \mathrm{~g} / \mathrm{L}, 5 \mathrm{~g} / \mathrm{L}$ and $8 \mathrm{~g} / \mathrm{L}$, respectively. Likewise, that of the phenols with respect to the catalyst concentration were $40 \%, 43 \%$ and $60 \%$. In addition, an increase in the catalyst concentration from $2 \mathrm{~g} / \mathrm{L}$ to $5 \mathrm{~g} / \mathrm{L}$ had almost no degradation on the phenols. This might be due to the low presence of reactive radicals of the catalyst to degrade the phenol as compared with the catalyst dosage of $8 \mathrm{~g} / \mathrm{L}$ which produced a high surface area for the adsorption of the phenols. Therefore, it is advisable to use a catalyst-loading rate which degrades both contaminants at a constant run time and airflow rate [8].

\subsection{Effects of Run Time}

It was found that effective degradation requires an economical contact time between the light intensity and the catalyst. Fig. S2 shows that increasing the run time increases the degradation of both oil (SOG) and phenol. However, the degradation of the phenol was rapid while that of the oil was gradual. The average oil degradation at 30, 60 and 90 min were $75 \%$, 85\% and $90 \%$, respectively. Likewise, the phenol degradation observed were $35 \%, 45 \%$ and $55 \%$, respectively to the run time.

\subsection{Effect of Air Flowrate}

The addition of the dissolved air generated microbubbles increased the oxidation reaction rate for the contaminant degradations. It also assisted in keeping particles in suspension and the catalyst interacting with the effluent contaminants. However, increasing the air flowrate changed the phenomenon of the microbubbles to larger bubbles which created turbulence, thereby breaking the cohesion force that binds the nanoparticles and oil droplets together. Hence, decreasing the degradation of the ORW. Therefore, the lower the air flowrate the better the microbubbles generated to enhance the degradation.

Fig. S3 shows that increasing the airflow rate decreased the degradation of oil (SOG) and phenol. It was found that at an air flowrate of $0.768 \mathrm{~L} / \mathrm{min}, 1.11 \mathrm{~L} / \mathrm{min}$ and $1.48 \mathrm{~L} / \mathrm{min}$; the oil (SOG) degradation, respectively decreased as $95 \%$, 85\% and $65 \%$, while that of the phenol also decreased as $75 \%, 45 \%$ and $35 \%$, respectively for the air flowrates. This confirms a report by Hasan et al [18] that increasing the air flowrate has a significant effect on photolytic degradation retardation, thus the moderate rate contributed to the agglomeration of the catalyst and the contaminant particles.

\subsection{Optimization Using RSM}

A BBD matrix with three factors and the results of experimental runs in terms of photocatalytic removal of the oil (SOG) and phenol at an initial concentration of $40 \mathrm{mg} / \mathrm{L}$ and $3 \mathrm{mg} / \mathrm{L}$, respectively are shown in Table S2. According to the design matrix, 17 experimental runs were obtained and the data collected were analysed using the ANOVA. A second-order polynomial model was derived, where the data were well-fitted and the statistical significance of the models were acceptable.

The reduced form of the models expressed as a function of the input and output parameters, are represented in their coded $(10 ; 12)$ and actual $(11 ; 13)$ equations for oil (SOG) and phenol degradation, respectively. It was deduced that the data obtained fitted well to the response quadratic model. Furthermore, the analysis of residuals was performed for evaluating the model adequacy.

$$
\begin{gathered}
\text { Coded Oil (SOG) model }= \\
86.26+1.13 \mathrm{~A}-5.4 \mathrm{~B}+13.07 \mathrm{C}-2.58 \mathrm{AB}- \\
0.3616 \mathrm{AC}+3.59 \mathrm{BC}-2.26 \mathrm{~A}^{2}-4.96 \mathrm{~B}^{2}-20.41 \mathrm{C}^{2}(10) \\
\text { Actual Oil (SOG) model }= \\
-163.442+4.988 \mathrm{~A}+0.245 \mathrm{~B}+380.21 \mathrm{C}- \\
0.0286 \mathrm{AB}-0.338 \mathrm{AC}+0.336 \mathrm{BC}-0.251 \mathrm{C}^{2}- \\
0.0055 \mathrm{~B}^{2}-161.018 \mathrm{C}^{2} \\
\text { Coded Phenol model }= \\
40.38+4.76 \mathrm{~A}-8.43 \mathrm{~B}+9.58 \mathrm{C}-6.67 \mathrm{AB}+ \\
9.08 \mathrm{AC}-4.93 \mathrm{BC}-4.59 \mathrm{~A}^{2}+7.92 \mathrm{~B}^{2}-1.63 \mathrm{C}^{2} \\
\text { Actual Phenol model }= \\
16.15+12) \\
0.474 \mathrm{~A}-0.44 \mathrm{~B}+41.017 \mathrm{C}-0.074 \mathrm{AB}+8.49 \mathrm{AC}- \\
0.509 \mathrm{~A}^{2}+0.00879 \mathrm{~B}^{2}-12.856 \mathrm{C}^{2}
\end{gathered}
$$


It is observed that all the factors had an influence on the PCD of the contaminants. Nevertheless, the interaction between the reaction rate and aeration rate (BC) had an effective positive degradation of the oil (SOG). This is due to their high positive coefficient term. Likewise, the combination of the catalyst concentration and aeration time (AC) had a significant positive influence on the phenol degradation. The negative second-order terms and other terms were attained for all the factors studied, that corresponded to concave surfaces showing a higher rate of decrease of oil (SOG) and phenol removal efficiency.

\subsection{ANOVA for the Oil (SOG) and Phenol Degradation}

The model accuracy is confirmed through the comparison between actual values and the predicted ones. The results show good accuracy of the model. The model significance and adequacy have been examined by means of ANOVA (Table S3 and S4) for the oil and phenol. Also good model predictability can be approved by the lack of fit test (not significant in this case) corresponding to the absolute error. Furthermore, the analysis of residuals was performed for evaluating the model adequacy.

In Table S3, the low value of the coefficient of variation (CV $=10.81 \%$ ) confirms good accuracy of the model. The statistical values including $p$-value 0.0017 and F-value of 6.36 reveal the high model's significance. The $p$-values less than 0.0500 indicate model terms are significant, and this makes the terms $\mathrm{C}$ and $\mathrm{C}^{2}$ to be part of the model terms. There is only a $1.17 \%$ chance that the F-value of the model could happen because of error. Considering $\mathrm{R}^{2}$ of 0.9966 , the variability of $99.66 \%$ could be described sufficiently via the obtained results and accordingly the overall variation of $0.34 \%$ remained inexplicable. The adjusted coefficient value of 0.9613 and its reasonable $R^{2}$ values reveals a good predictability of the model.

In Table S4, the low value of the coefficient of variation (CV $=9.25 \%$ ) confirms good accuracy of the model. The statistical values including a $p$-value of 0.0004 and $\mathrm{F}$-value of 18.59 reveal the high model's significance. There is only a $0.04 \%$ chance that the F-value of the model could happen because of error. Considering $\mathrm{R}^{2}$ of 0.9798 , the variability of $97.98 \%$ could be described sufficiently via the obtained results and accordingly the overall variation of $4.02 \%$ remained inexplicable. The adjusted coefficient value of 0.9613 and its reasonable consistency with $\mathrm{R}^{2}$ reveals a good predictability of the model. The predicted R-squared and adjusted $\mathrm{R}$-squared values are in reasonable agreement. This means the ability of both models to provide good prediction is high and can be used to navigate the design space well.

The significance of the models were found to have high correlation coefficients $\left(\mathrm{R}^{2}\right)$ of $97.66 \%$ and $97.98 \%$ for the oil (SOG) and phenol, respectively, which validates how well the models fit the experimental data as depicted in Fig. S1 and S2. In addition, the plot demonstrated the predicted verses actual values for the degradation of the oil (SOG) and phenol, respectively. In Fig. S4, the vertical line of residuals is observed in the region between $30 \%$ and $90 \%$. In addition, in Fig. S5, the points are in close proximity to the regression line with a percentage probability range of $20 \%$ to $70 \%$. Fig. S6 and Fig. S7 also depict the normal probability plots for SOG and phenol degradations. In both graphs (Fig. S6 and S7), the residues are linearly scattered, thus, the data points are very close to the regression line indicating a good fit of the model to the data.

\subsection{Numerical Optimization by Perturbation Plot}

The numerical optimization procedure was performed applying a desirability approach to discover the distinct settings which give the maximize removal of the oil and phenol. The main interactive factors that have influence (catalyst concentration) on the response were identified by performing the perturbation plot as presented in Fig. S8 with their coded values, where a desirability degradation of $68 \%$ was found. Subsequently, almost the same desirability was obtained at the different conditions as depicted in Table 3 . In this case, the option 1 was opted to be best conditions with degradation of oil (80.7\%) and phenol (66.3\%) by using their respective models to obtain the same desirability (68.1\%). This occurred at a catalyst concentration of $2 \mathrm{~g} / \mathrm{L}$, a run time of $30 \mathrm{~min}$ and an airflow rate of $1.04 \mathrm{~L} / \mathrm{min}$.

\subsection{Graphical Optimization and Confirmation Test}

The interactive factors of the PCR system were graphically evaluated to enhance the polishing step in the treatment of ORW to be economically viable. A desirable goal for the catalyst concentration, reaction time and air flowrate were set to be within their respective range of the design space as depicted in Fig. S9. It was found that, an increase in the catalyst concentration increased the degradation of the contaminants at economic time rate (30 $\mathrm{min})$; thus, the longer time will result in high energy utilisation by the system which will increase the cost of production. Therefore, using a catalyst concentration of $7.8 \mathrm{~g} / \mathrm{L}$ and aeration rate of $1.34 \mathrm{~L} / \mathrm{min}$, about $86 \%$ of the oil and $78 \%$ of the phenol were degraded with a desirability efficiency of $69 \%$. The result obtained was in good agreement with the experimental results as shown in Fig. 2.

The visual representation of the response surface in 3D and 2D contour plots assisted the investigation and optimization of the PCD system, by determining the maximum region of interest. The precise location and optimum point identified (Fig. 3 and 4).

Table 3. BBD Optimum Conditions

\begin{tabular}{ccccccc}
\hline ID & Catalyst concentration (g/L) & Run time (min) & Air flow rate (L/min) & Oil (SOG) (\%) & Phenol (\%) & Desirability (\%) \\
\hline 1 & 2 & 30 & 1.04 & 80.72 & 66.34 & 68.1 \\
2 & 2 & 30 & 1.17 & 80.54 & 66.24 & 65.1 \\
3 & 2 & 30 & 1.15 & 81.00 & 66.49 & 64.1 \\
4 & 2 & 30 & 1.17 & 80.26 & 66.09 & 65.1 \\
5 & 2 & 30 & 1.18 & 80.07 & 65.98 & 65.1 \\
\hline
\end{tabular}


- Phenol (\%) $\quad \boldsymbol{c}$ Oil (SOG) (\%)

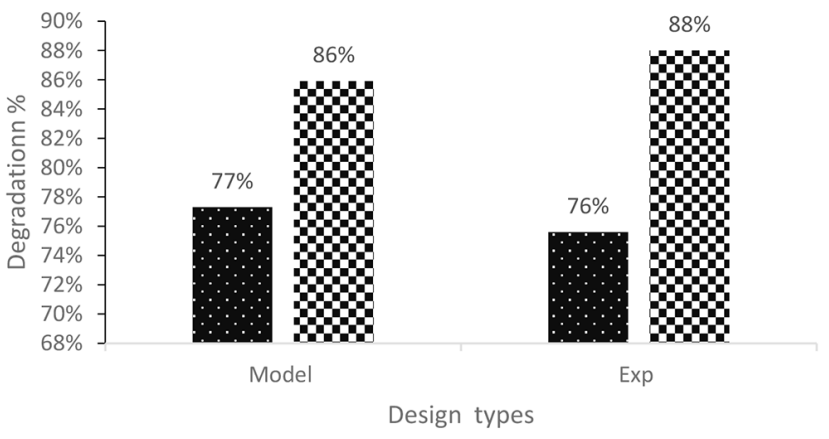

Fig. 2. Comparing model prediction and experimental results of optimum condition at time (30 $\mathrm{min})$, catalyst concentration $(7.8 \mathrm{~g} / \mathrm{L})$ and aeration rate $(1.34 \mathrm{~L} / \mathrm{min})$.
The response 3D surface and the contour plots shows the models variation with two factor levels (catalyst concentration and run time) at a mediocre amount of aeration rate obtained from RSM model. In addition, the plots depict the sensitivity of the responses due to the change of factor levels with the degree of their interactions. Thus, when the catalyst concentration increases, photocatalyst rapidly agglomerates with a reducing ability of effective absorption of the contaminant. Hence, the degradation reaction rate decreases due to a reduction of positive electron hole and the obtained oxidizer radicals [15, 18].

\section{Conclusions}

The performance of employing photocatalytic $\mathrm{TiO}_{2}$ in the presence of UV radiation and air on degradation of the oil (SOG) and phenol
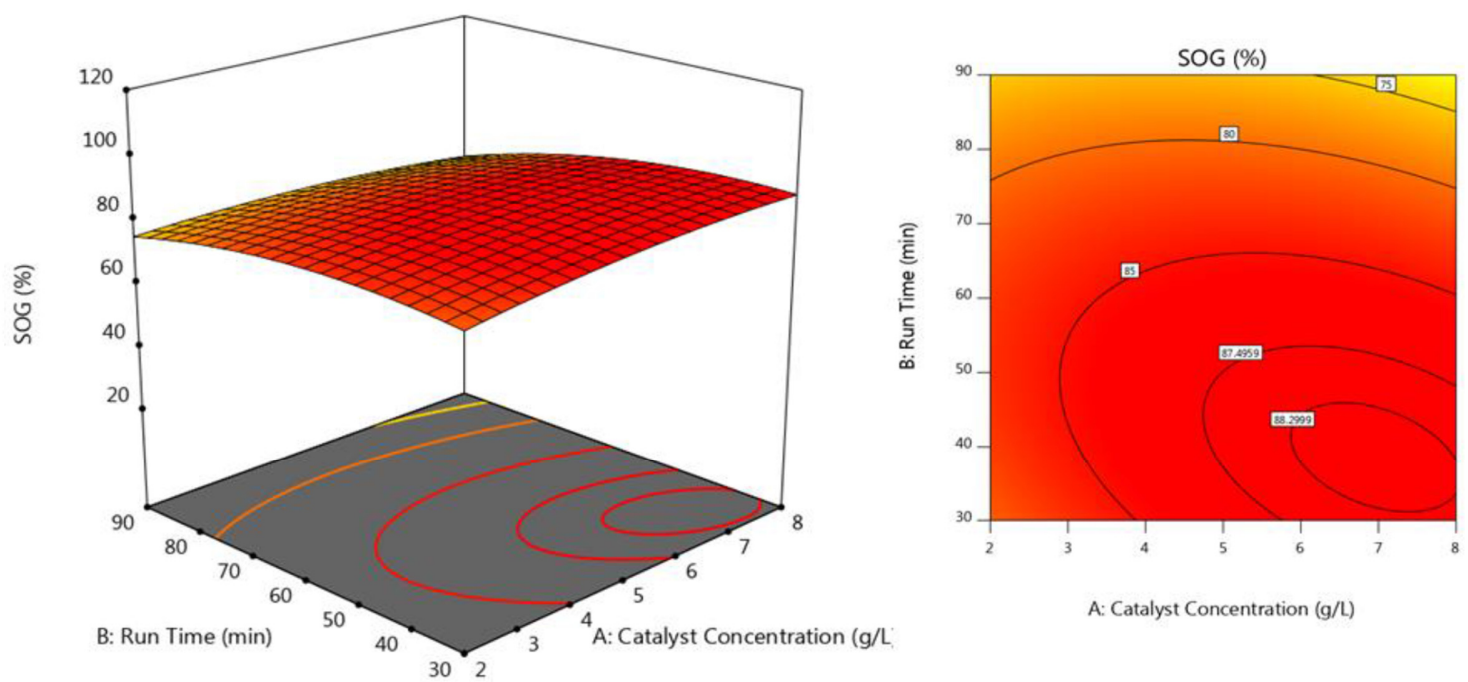

Fig. 3. The $3 \mathrm{D}$ and contour plot of oil (SOG) model.

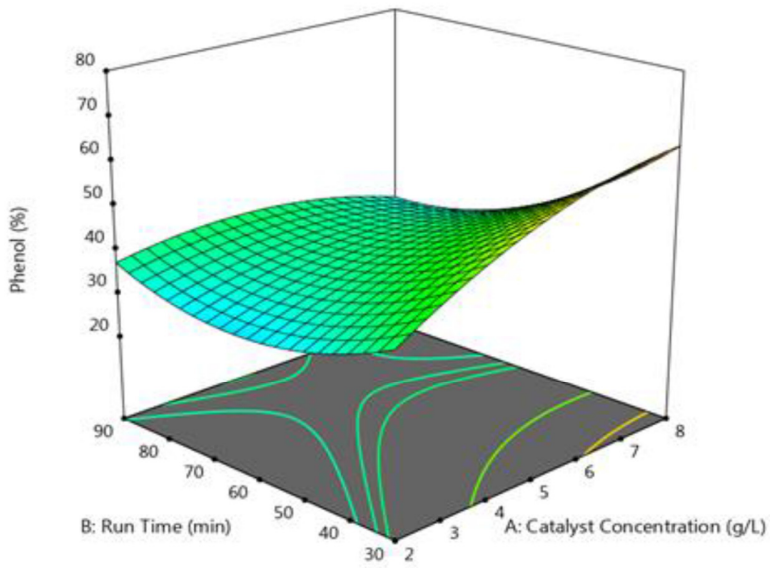

Fig. 4. The 3D and contour plot of phenol model.

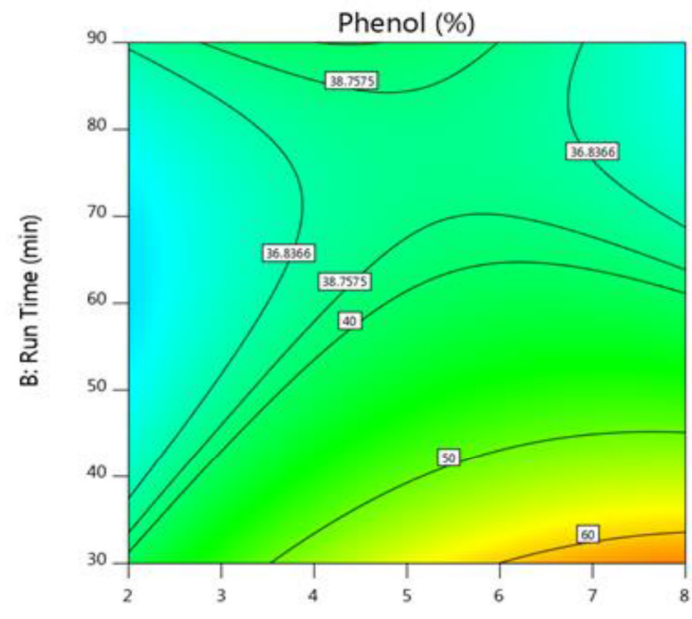

A: Catalyst Concentration $(\mathrm{g} / \mathrm{L})$ 
from petroleum wastewater was studied. It was deduced that the catalyst in the presence of the UV light and aeration (oxygen) supported the oxidation reaction, which converted the harmful organic contaminants into $\mathrm{CO}_{2}$ and $\mathrm{H}_{2} \mathrm{O}$. The OFAT approach demonstrated the need to obtain optimum conditions and identify the interactive factor to maximize the degradation rates of SOG and phenol. This was essential for any practical application of photocatalytic oxidation processes in ORW treatment techniques, which has not been explored much by the crude refining industry. The BBD adapted from the RSM was successfully applied to optimize and evaluate the relationship between the operating conditions viz catalyst concentration, run time and airflow rate. It was found that all factors investigated had considerable influences rate on the photocatalytic degradation performance. The two response quadratic models developed for the oil (SOG) and phenol were significant with very low $p$-values $(p<0.0001)$. The models predictions were in good agreement with the experimental results with a desirability of $68 \%$, and the oil (SOG) and phenol degradation rates of $80.7 \%$ and $66.3 \%$, respectively. The obtained optimum conditions included the catalyst concentration of $2 \mathrm{~g} / \mathrm{L}$, a run time of $30 \mathrm{~min}$ and an airflow rate of $1.04 \mathrm{~L} / \mathrm{min}$.

\section{Acknowledgments}

The authors wish to thank Durban University of Technology, Department of Chemical Engineering, South Africa for supporting this project.

\section{References}

1. Zhai J, Huang Z, Rahaman MH, et al. Comparison of coagulation pretreatment of produced water from natural gas well by polyaluminium chloride and polyferric sulphate coagulants. Environ. Technol. 2017;38:1200-1210.

2. El-Naas MH, Alhaija MA, Al-Zuhair S. Evaluation of a three-step process for the treatment of petroleum refinery wastewater. J. Environ. Chem. Eng. 2014;2:56-62.

3. El-Naas MH, Alhaija MA, Al-Zuhair S. Petroleum refinery wastewater treatment: A pilot scale study. J. Water Process Eng. 2016;14:71-76.

4. Nasir N, Daud Z. Performance of aluminium sulphate and polyaluminium choloride in biodiesel wastewater. J. Mech. Eng. Sci. 2014;7:1189-1195.

5. Diya'Uddeen BH, Daud WMAW, Abdul Aziz AR. Treatment technologies for petroleum refinery effluents: A review. Process Saf. Environ. Prot. 2011;89:95-105.
6. Tetteh EK, Rathilal S. Application of response surface methodology (RSM) - Reduction of industrial wastewater chemical oxygen demand. In: CBU International Conference Proceedings. Central Bohemia Univ.; 2017. p. 1226-1232.

7. Yan L, Wang Y, Li J, et al. Comparative study of different electrochemical methods for petroleum refinery wastewater treatment. Desalination 2014;341:87-93.

8. Tony MA, Purcell PJ, Zhao YQ, Tayeb AM, El-Sherbiny MF. Photo-catalytic degradation of an oil-water emulsion using the photo-fenton treatment process: Effects and statistical optimization. J. Environ. Sci. Health A Tox/Hazard. Subst. Environ. Eng. 2009;44:179-187.

9. Sahu OP, Chaudhari PK. Review on chemical treatment of industrial waste water. J. Appl. Sci. Environ. Manag. 2013;17: 241-257.

10. Jiang C, Xu Z, Guo Q, Zhuo Q. Degradation of bisphenol $\mathrm{A}$ in water by the heterogeneous photo-Fenton. Environ. Technol. 2014;35:966-972.

11. Lazar MA, Varghese S, Nair SS. Photocatalytic water treatment by titanium dioxide: Recent updates. Catalysts 2012;572-601.

12. Somensi CA, Simionatto EL, Bertoli SL, Wisniewski A, Radetski CM. Use of ozone in a pilot-scale plant for textile wastewater pre-treatment: Physico-chemical efficiency, degradation by-products identification and environmental toxicity of treated wastewater. J. Hazard. Mater. 2010;175:235-240.

13. Ghasemi Z, Younsei H, Zinatizadeh AA. Preparation, characterization and photocatalytic application of $\mathrm{TiO}_{2} / \mathrm{Fe}-\mathrm{ZSM}-5$ nanocomposite for the treatment of petroleum refinery wastewater: Optimization of process parameters by response surface methodology. Chemosphere 2016;159:552-564.

14. Tetteh EK, Rathilal S, Chollom M. Evaluation of the coagulation floatation process for industrial mineral oil wastewater treatment using response surface methodology (RSM). Int. J. Environ. Impact. 2018;1:491-502.

15. Shaykhi ZM, Zinatizadeh AAL. Statistical modeling of photocatalytic degradation of synthetic amoxicillin wastewater (SAW) in an immobilized $\mathrm{TiO}_{2}$ photocatalytic reactor using response surface methodology (RSM). J. Taiwan Inst. Chem. Eng. 2014;45:1717-1726.

16. APHA, AWWA, WEF. Standard methods for the examination water and wastewater. Stand. Methods. 2012;541:1360.

17. Tetteh EK, Rathilal S, Robinson K. Treatment of industrial mineral oil wastewater - Effects of coagulant type and dosage. Water Pract. Technol. 2017;12:139-145.

18. Hasan DB, Abdul Aziz AR, Daud WMAW. Oxidative mineralisation of petroleum refinery effluent using Fenton-like process. Chem. Eng. Res. Des. 2012;90:298-307. 